\title{
¿Competitivas o complementarias? El debate agrario francoespañol en la transición democrática, 1975-1982
}

Sergio Molina

\begin{abstract}
PALABRAS CLAVE: relaciones internacionales, Francia, España, construcción europea.
\end{abstract}

\section{CÓdIGOS JEL: F13, F15, N54, Q17.}

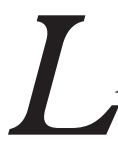

os retrasos en la adhesión de España a la CEE siempre se han atribuido a la problemática agraria francoespañola. El conflicto se basó en la existencia de competencia entre los cultivos de ambos países. Más de cuarenta años después, se mantiene la idea de que el factor más importante de esta problemática fue el económico. Sin embargo, hasta el momento apenas existen análisis cuantitativos que hayan demostrado si la situación de competencia fue real. Ante esta situación, el objetivo principal del artículo es analizar y comparar las estadísticas agrarias de producciones y rendimientos de Francia y de España para comprobar si las agriculturas de los dos países era complementarias o competitivas. En un segundo plano, se mostrará la opinión de los dos gobiernos con el propósito de incluir el factor político en esta cuestión. Todo ello en el periodo de la Transición española, 1975-1982, un momento en el que la inestabilidad interna estuvo acompañada de las dificultades para la integración en la CEE y del contexto propio de la Guerra Fría. 


\section{Competitive or complementary? The french-spanish agricultural debate during the spanish democratic transition (1975-1982)}

\section{KEYWORDS: international relations, France, Spain, European con- struction.}

\section{JEL CODES: F13, F15, N54, Q17.}

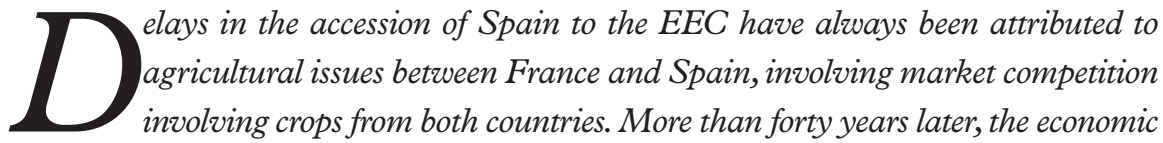
factor is still thought to be the most critical in this issue. However, there are scarcely any quantitative studies to date that have shown whether the competitive situation was real. The aim of this paper is to analyse and compare agricultural production and yield statistics from France and Spain, in order to determine if agriculture was competitive or complementary in these two countries. Opinions from both governments are also included, to better understand political factors in this situation. This took place during the Spanish transition to democracy (1975-1982), a time of internal instability accompanied by the difficulties of integration in the EEC and within the international context of the Cold War.

Sergio Molina [orcid.org/0000-0003-0766-1082] es doctor en Historia Contemporánea por la Universidad de Castilla-La Mancha. Dirección para correspondencia: Seminario de Estudios del Franquismo y la Transición en la Facultad de Humanidades de Albacete, Universidad de Castilla-La Mancha, Campus Universitario s/n, Edificio Benjamín Palencia,020071,Albacete (España).C.e.: Sergio.Molina@uclm.es 


\section{INTRODUCCIÓN}

Los cambios políticos iniciados tras la muerte del dictador en 1975 afectaron también a la posición de España en Europa. Las aspiraciones sociales y la necesidad de legitimar el nuevo sistema democrático fueron algunas de las razones por las que España solicitó la adhesión a la CEE en 1977. Sin embargo, hubo que esperar a 1986 para poder firmar el tratado de integración. El paso de nueve años en procesos de negociación es una muestra de las dificultades que existieron para llegar a un acuerdo (Núñez Peñas, 2013). De todas las cuestiones que se trataron, el asunto agrario fue el que más controversia causó. El motivo principal era el potencial agrícola español y su capacidad de crecimiento. Estos argumentos fueron los expuestos por los agricultores franceses y por su Gobierno ante los consejos de ministros comunitarios. Pero también por el Gobierno español para justificar el retraso de la integración. Se generalizó un discurso en el que la agricultura mediterránea francesa y la española se encontraban en una situación de competencia debido al cultivo de los mismos productos (Molina, 2018a). Todo ello en un contexto de crisis comunitaria, provocada, en parte, por el bloqueo británico de la PAC y por los excedentes lácteos desde finales de la década de los sesenta. Por otro lado, la incertidumbre en España sobre el futuro de la incipiente pero débil democracia marcó todas las decisiones políticas nacionales e internacionales (Sartorius \& Sabio, 2007).

La principal hipótesis es que el conflicto agrario francoespañol no fue un affaire únicamente de competencia productiva. Los argumentos económicos no pueden responder a algunas lógicas de este conflicto, como, por ejemplo, el cambio de discurso del RPR (Rassemblement pour la République) tras su fracaso en las elecciones presidenciales de $1981^{1}$. Por ello, pensamos que la problemática agraria acabó teniendo un trasfondo más político que económico. Sin embargo, para poder corroborar esa hipótesis, el primer paso es comprobar si la competencia agraria era tan importante como se afirmó en aquellos momentos, y ese es el objetivo de este artículo $^{2}$. Se pretende analizar las producciones de ambos países a través de estadísticas cuantitativas para poder dar respuesta a la siguiente pregunta: clas agriculturas francesa y española eran incompatibles o, por el contrario, podían complementarse dentro del Mercado Común? Una vez contestada esta cuestión, de manera breve se contrastarán dichos datos con los informes internos del Gobierno y se apuntarán algunas causas por las que el factor político pudo ser importante a ambos la-

1. El RPR fue el partido heredero del Gaullismo liderado por Jacques Chirac. Se trató de uno de los partidos que más incidió en la competitividad de los productos españoles desde 1975. Sin embargo, tras sus malos resultados de 1981 reconocieron que esa estrategia de enfrentamiento contra el Gobierno no había funcionado y decidieron moderar su posición con respecto a la adhesión española.

2. Quizás uno de los documentos más representativos fue CNJA (1976). 
dos de los Pirineos. El análisis se centrará exclusivamente en el periodo de la transición (1975-1982), ya que las dinámicas de las relaciones bilaterales y de las negociaciones con la CEE cambiaron tras la victoria de Felipe González. Con el Gobierno socialista se introdujeron nuevos factores no solo nacionales, sino también internacionales (acuerdos de Fontainebleau, 1984) que necesitarían un estudio independiente y basado en los datos que se ofrecerán en este artículo.

La investigación se ha estructurado en cuatro apartados: el primero de ellos enmarcará las agriculturas de ambos países, las relaciones bilaterales y la situación de la PAC en la década de los setenta; en el segundo epígrafe se mostrará una comparación de las estadísticas de producciones, rendimientos y balanzas comerciales de las producciones francoespañolas; en el tercer punto se someterá todo lo anterior a un análisis en función de los documentos del Gobierno francés, para finalizar el texto con una conclusión que permita responder a la cuestión principal planteada anteriormente.

Una de las principales motivaciones para analizar esta problemática ha sido la escasa atención que han recibido las relaciones agrarias bilaterales, pese a su relevancia histórica. Los exiguos análisis que aluden a estas cuestiones fueron realizados en la década de los ochenta por Carlos Tió (1986) o Arturo Camilleri (1984) ${ }^{3}$. No obstante, son estudios que muestran datos sobre la adhesión de España en términos generales y no específicos de la relación con Francia. Este déficit analítico justifica el interés sobre este asunto. Ante esta situación, gran parte de la información ha sido obtenida de fuentes primarias. Los anuarios de agricultura de cada uno de los países, las estadísticas de la FAO y los numerosos informes referidos a esta cuestión realizados a ambos lados de los Pirineos han sido el pilar de la investigación. Todos ellos poseen características uniformes que permiten su comparación gracias a que son datos oficiales y han sido elaborados con las mismas unidades de medida. Además, muchos de ellos estaban realizados a partir de las mismas fuentes, por lo que los criterios utilizados son similares. No obstante, los datos españoles estuvieron condicionados por el contexto de la Transición, en el que se produjeron numerosos cambios legislativos (sobre cuestiones agrarias, económicas y políticas), además de por la crisis económica. La inexistencia de archivos homogéneos de los ministerios de Agricultura y el análisis de una cuestión bilateral provoca que la información esté dispersa en multitud de fondos diferentes. Para la realización de esta investigación, se ha consultado el Archivo General de la Administración, la Hemeroteca Municipal de Madrid y el Archivo del Ministerio de Agricultura en España; y los Archives Nationales, los Archives Diplomatiques du Ministère des Affaires étrangères (París y Nantes) y la Bibliothèque Nationale François Mitterrand en Francia. Todo ello acompañado de una im-

3. Se pueden añadir algunos otros: Pedro SolbES (1979) y Bernard Roux (1988). 
portante base bibliográfica de la situación agraria nacional de ambos países, que aparece reflejada al final del texto.

\section{LAS AGRICULTURAS NACIONALES Y COMUNITARIAS}

La Política Agraria Común se puso en marcha en 1962 con el objetivo de establecer un mercado interno libre de aduanas entre los seis países miembro y, al mismo tiempo, eliminar las diferencias socioeconómicas entre los agricultores y el resto de los trabajadores europeos (Petit, 2016: 44-45; Bureau \& Thoyer, 2014). Esta iniciativa surgió en la Francia de Charles de Gaulle para consolidarse como la despensa comunitaria, principalmente porque era el único país capaz de cultivar productos nórdicos y mediterráneos (Ries, 1982: 82-83). Además, tras el apoyo del mundo agrario francés al totalitarismo en los años veinte, para el Gobierno era crucial el apoyo del campesinado a las políticas agrarias comunitarias. Uno de los principios vertebradores de la PAC fue el proteccionismo frente a productos agrícolas de terceros países, para obligar a los Estados miembro a consumir productos internos. Mientras tanto, el mercado agrícola europeo estaba protegido por mecanismos como los derechos de aduana, los precios referencia o un sistema de calendarios para aislarse de la competencia internacional. Sin embargo, la demanda de productos era mayor que la oferta y esa situación obligaba a la CEE a recurrir al mercado mundial para cubrir esos déficits. Además, la dependencia de los factores climáticos provocaba que con frecuencia las cosechas fuesen inestables y eso les obligaba a importar en el caso de necesidad. Con esos propósitos la CEE firmó diversos acuerdos preferenciales con ciertos países mediterráneos, uno de ellos con España (1970). Estos tratados les permitían entablar relaciones económicas tanto industriales como agrarias.

En líneas generales, la PAC permitió desarrollar un comercio interno positivo y potenció la agricultura en los países europeos, sobre todo en Francia y en Italia (Blumann, 2009). Sin embargo, con el paso de los años fueron apareciendo diferentes conflictos: el surgimiento de excedentes en el sector lácteo a finales de los sesenta o la negativa de Thatcher a mantener los presupuestos de la PAC en 1979 (debido al escaso peso de la agricultura en Gran Bretaña) demostraron que los intereses nacionales primaban sobre los comunitarios (Patel, 2009). Ese fue uno de los motivos por los que fue tan costoso que la unión económica diera lugar a una unión de carácter político. La pugna entre visiones nacionalistas venía motivada en muchas ocasiones por la importancia de este sector en cada uno de los socios comunitarios. Los países de la CEE se pueden dividir entre los productores agrícolas y los no productores. El enfrentamiento entre ambos no solo aparecía a la hora de fijar el presupuesto de la PAC, sino también en los procesos de adhesión de los países del sur. Para Francia, la integración española no sería posible sin un periodo 
largo de transición y una reforma de la PAC, mientras que para Alemania o para Gran Bretaña debía ser un proceso rápido. El razonamiento de estos países era muy sencillo: la ampliación hacia el sur de Europa aumentaría la facilidad de compra de productos agrarios españoles a un precio menor que los establecidos por Francia o Italia.

Tras la Segunda Guerra Mundial la agricultura tradicional entró en crisis ante las nuevas demandas sociales de consumo y de producción. La motorización y el auge de la industria agroalimentaria revolucionaron la manera de entender el sector. Francia fue un ejemplo de todos esos cambios, denominados con el término revolución verde. En este país se potenció una agricultura motomecanizada, industrializada y de grandes explotaciones. La economía de mercado se adentró en el sector agrario, el paysan se transformó en un agriculteur-entrepreneur (Chupin \& Mayance, 2016: 9; Hervieu \& Purseigle, 2013: 111, 119), el consumo de productos frescos dio paso a los productos elaborados y, en consecuencia, a la industria agroalimentaria (Malassis, 1997). En el centro y norte del país, donde abundaban los cereales y la ganadería, se consiguió dicho objetivo, pero en la mitad meridional, las producciones vinícolas y hortofrutícolas mantuvieron en gran medida la estructura tradicional y familiar (Bessière, 2014; Bucarut, Moyne \& Pollina, 1996). Esto, junto con las diferencias entre los altos beneficios del cereal y de los ganaderos y la menor rentabilidad de las producciones del sur, generó ciertos enfrentamientos en el seno de los agricultores franceses, aunque nunca fueron más allá de disputas internas ${ }^{4}$. A estos cambios se les unieron tres características particulares. En primer lugar, se trataba de un sector muy bien organizado y preocupado por sus intereses, pero monopolizado por un único sindicato (Hervieu \& Purseigle, 2013: 189-205). La Fédération nationale des syndicats d'exploitants agricoles (FNSEA) y su representación juvenil, el Centre national des jeunes agriculteurs (CNJA). En segundo lugar, el agro francés tenía una gran influencia en el poder político. Esa característica permite hablar de un lobby agrario, pese a que no era un sector decisivo en la economía francesa. En 1977, por ejemplo, representaba un $5 \%$ del PIB nacional y, sin embargo, mantuvo su incidencia en la política como herencia de la Tercera República (Bertrand, 2010). Por último, se debe resaltar la combatividad de los agricultores franceses. El análisis de la historia de la agricultura en Francia muestra las intensas luchas que han mantenido en contra de las diferentes administraciones con el objetivo de defender sus intereses. En el marco cronológico de este análisis se pueden identificar fácilmente los conflictos de los agricultores contra los vinos argelinos e italianos, contra las cuotas lecheras comunitarias, los productos mediterráneos españoles y, en general, contra la necesidad de adaptar la PAC al nuevo contexto (Bruneteau, 1993; Roger, 2011; Molina, 2018b).

4. A estas diferencias se les podría añadir otra de tipo ideológico. En el sur, la izquierda tenía más importancia entre los agricultores que en el norte. 
El sector agrario español presentaba diferencias importantes con respecto al francés. La modernización impulsada tras la crisis de la agricultura tradicional, aunque mejoró sustancialmente la situación, no tuvo los mismos efectos que en Europa. Principalmente por la permanencia de la dictadura, por el atraso acumulado desde la década de los cuarenta y por su aislamiento internacional. El asociacionismo agrario se estaba vertebrando en esos momentos, la inversión tanto pública como privada hasta la fecha había sido inferior a la necesaria para la introducción de la modernización, las políticas agrarias adoptadas habían tenido consecuencias negativas a medio plazo. Un ejemplo de esas políticas fue el proteccionismo de cultivos poco competitivos, pues no facilitó que se adaptasen a los precios y los costes de sus homólogos europeos (Fernández, 2012: 41-76). Pese a que los indicadores de la Tabla 1 hacen referencia a algunos de esos problemas, desde la década de los sesenta comenzaron a introducirse cambios de manera progresiva, y muchos de ellos se consolidaron en el periodo de la Transición. En el sector vinícola se apostó por las cooperativas para mejorar la producción de vino y su comercialización (Medina, 2016), en el sector cárnico, el aumento del consumo de estos productos gracias a la mejora económica permitió un crecimiento exponencial del sector avícola y de huevos (Cussó \& Garrabou, 2007: 69-100; Domínguez Martín, 2001: 47-83), y en general, se incrementaron las exportaciones (Clar, Serrano \& Pinilla, 2015: 149-186). Sin embargo, ese periodo de crecimiento y modernización se vio frenado por la crisis del petróleo de 1973. La principal consecuencia de la tecnificación agrícola fue la dependencia energética del sector $\mathrm{y}$, ante el aumento de los precios del petróleo, los agricultores vieron disminuidas sus rentas (Sumpsi, 1982: 185-193; Abad \& Naredo, 2002: 81-142). A esos problemas se les añadía la dependencia de los inputs, entre los que destacaban los piensos. Así, en 1980 el porcentaje de producción ganadera sobre la total agraria en Francia era del 63,51\%, mientras que en España únicamente del 33,46\% (Clar, Martín Retortillo \& Pinilla, 2015: 24). Además, en el periodo de la Transición, las políticas agrarias no siempre permitieron el desarrollo del sector (Clar, 2005). Según José María Sumpsi, se pueden diferenciar dos etapas. La primera de ellas, entre 1975 y 1977, se caracterizó por la inestabilidad en el cargo de ministro de Agricultura y las escasas medidas adoptadas para revertir la situación. Muchas de ellas se concretaron en los Pactos de la Moncloa y se centraron en mantener controlado al nuevo sindicalismo democrático. La segunda fase corresponde con el mandato de Jaime Lamo de Espinosa como ministro entre 1978 y 1981. En este periodo se llevaron a cabo reformas que permitieron en ciertas ocasiones revertir la situación anterior: se fomentó la iniciativa privada de regadío, se desarrolló la ganadería y se pusieron en marcha las Organizaciones Profesionales Agrarias (OPAS), las políticas antiinflacionistas y una nueva ley de financiación agraria. Sin embargo, con respecto a la adhesión, durante estos años se mantuvieron las políticas de Estado proteccionistas para ciertos productos, como los hortofrutícolas, lo que impedía la homologación entre las agriculturas comunitaria y española (Sumpsi, 1983: 447-471). A todo ello 
se le unía, a diferencia de en el país galo, el enfrentamiento continuo entre el ministerio y las organizaciones agrarias vinculadas con la izquierda. Tanto la COAG (Coordinadora de Organizaciones de Agricultores y Ganaderos) como la FTT (Federación Nacional de Trabajadores de la Tierra $)^{5}$ reclamaron medidas más efectivas, una liberalización de las cámaras agrarias, y más participación en la construcción de la nueva política agraria y en los debates sobre la adhesión ${ }^{6}$; pues, pese a la propaganda del Gobierno, no todos los sectores agrarios defendían la adhesión. El sector agrario canario, al igual que la patronal (Confederación Española de Organizaciones Empresariales), advirtieron de los riesgos de aceptar la integración a cualquier precio ${ }^{7}$. Es decir, mientras que las fuerzas políticas españolas apoyaron de manera unánime la adhesión, desde ciertos sectores agrarios se señalaban algunos problemas como consecuencia de la homologación comunitaria.

TABLA 1

Comparativa de datos de las agriculturas francesa y española, 1975-1981

\begin{tabular}{lcc}
\hline & Francia & España \\
\hline Población activa agraria 1975 & $10 \%$ & $23 \%$ \\
Población activa agraria 1980 & $8,17 \%$ & $17,5 \%$ \\
Número de tractores 1980 & 1.485 .000 & 491.000 \\
Hectáreas tierra cultivada 1980 & 17.212 miles & 20.500 miles \\
Aportación al PIB 1977 & $5 \%$ & $9 \%$ \\
Producción agropecuaria $1981^{8}$ & 110,6 & 98,38 \\
Balanza comercial agropecuaria 1979 & 9.928 .542 & 125.249 \\
\hline
\end{tabular}

Fuente: Annuaire de Graphiques Agricoles France (AGF) de 1982 y Anuario de la Agricultura Española (AAE) de 1983.

En último lugar, solo queda hacer referencia a los contactos bilaterales. Hasta el inicio de la Transición democrática, las relaciones entre ambos países siempre estuvieron condicionadas por el régimen dictatorial de España. A nivel político, el vínculo fue más limitado, pero a nivel económico, social, científico y técnico sí prosperaron numerosos pactos. En la década de los cincuenta, Francia concedió un préstamo a España de 15.000

5. La COAG estuvo ligada a CC. OO. y la FTT a UGT.

6. El País, 05/05/1978; 20/03/1979; 03/06/1979; 27/06/1979; 01/11/1979; у ABC, 28/07/1979.

7. Informe realizado por la patronal, recogido por la Embajada de Francia en julio de 1982. Archive Diplomatique de Paris (AMAE), 1930INVA/5138. Sobre Canarias, Archivo General de la Administración (AGA), leg. R.16571. "Informe reservado sobre el estado actual de los trabajos de preparación de las negociaciones", enero de 1979; Actualidad Agraria, 05/05/1982.

8. Producción agropecuaria por persona en 1981 (siendo el periodo 1974-1976 = 100).

9. Valores de importación y exportación de productos agropecuarios en cantidad sobre periodo base $1000 \$$. 
millones de francos (Sánchez Sánchez, 2006: 152), y desde los sesenta, el turismo, la emigración y los intercambios científico-técnicos acercaron a ambos países. Con respecto al tema agrario, en 1968 se configuró el Comité franco-español de Cooperación Agrícola para fijar precios, calendarios de comercialización y normativas sanitarias equiparables, y a partir de los setenta comenzaron a implantarse hipermercados franceses en la península, lo que supuso un cambio importante en la comercialización de los productos agrarios (Castro, 2010: 238-254). Con la democratización española las relaciones políticas también se intensificaron. Desde la muerte de Franco, Valéry Giscard d'Estaing buscó tener un protagonismo político en el futuro de España (Lemus, 2005; Cavallaro, 2013) y, al mismo tiempo, el Gobierno español fijó entre sus prioridades internacionales el acercamiento a Francia. Una prueba de ello fue la visita de Juan Carlos I a dicho país, pues fue el primer viaje oficial que realizó como monarca en Europa (Busturia \& Cantera, 1994: 136). Dichos contactos estuvieron condicionados por el tema aquí tratado y por otras problemáticas, como la pesca o la extradición de miembros de ETA (Morán, 1996). No obstante, el Gobierno francés, ante el desarrollismo económico español, intentó consolidarse en el mercado español con el objetivo de convertirse en el mayor proveedor de la península. En ese aspecto la prioridad era ganar posiciones frente a otros competidores extranjeros, como Alemania o EE. UU. (Sánchez Sánchez, 2006; Martin-Pañeda, 2015; Trouvé, 2008).

El índice cuantitativo más relevante para conocer el estado de las relaciones bilaterales en el plano comercial es la balanza de pagos. La Tabla 2 muestra cómo los intercambios comerciales fueron evolucionando favorablemente hacia España hasta consolidarse con un saldo positivo para este país. De esta manera, en 1979 Francia era el mejor cliente para los productos españoles, ya que el 16,1\% de las exportaciones españolas iban dirigidas al otro lado de los Pirineos ${ }^{10}$. Esta tendencia provocó que Francia fuese el único miembro de la CEE con una balanza comercial negativa con respecto a España, pero al mismo tiempo, era el Estado comunitario que más invertía en el país peninsular (el mayor inversor internacional era EE. UU.). El análisis detallado de los productos que se intercambiaban ambos países también ofrece datos relevantes. España compraba en su mayoría productos industriales y tecnológicos, mientras que Francia importaba una gran cantidad de cultivos primarios, aunque por detrás de productos automovilísticos ${ }^{11}$. Una vez llegados a este punto, si el objetivo de Francia había sido convertirse en la despensa de Europa y, tras Italia, era el mayor productor primario de la CEE, ¿por qué empleaba más de dos mil millones de francos en comprar este tipo de productos a España? Si se construyó un discurso contra la adhesión española por miedo a la competencia (Molina,

10. AMAE, 1929INVA/4377, informes fechados el 25/06/1980 y el 13/11/1980.

11. Los datos sobre los intercambios de 1979, en AMAE, 1929INVA/4377. 
2018a), ¿cuál es el motivo por el que acababan recurriendo al mercado primario español?

\section{TABLA 2}

Intercambios comerciales y balanza comercial de Francia en millones de francos, 1958-1979 (valores corrientes)

\begin{tabular}{lcccc}
\hline & $\mathbf{1 9 5 8}$ & $\mathbf{1 9 7 0}$ & $\mathbf{1 9 7 7}$ & $\mathbf{1 9 7 9}$ \\
\hline Exportaciones a España & 296 & 2.456 & 8.100 & 11.100 \\
Importaciones de España & 176 & 1.491 & 9.600 & 13.400 \\
Balanza comercial bilateral & +120 & +965 & -1.500 & -2.300 \\
Tasa de cobertura & 168,2 & 164,7 & 84,4 & 82,8 \\
\hline
\end{tabular}

Fuente: AMAE, 1929INVA/4377 y 187QO/421.

\section{AGRICULTURAS: ENTRE LA COMPETENCIA Y LA COMPETITIVIDAD}

El análisis cuantitativo se ha dividido en dos subapartados en función de la tipología de productos. Primero se analizarán los productos mediterráneos (frutas, hortalizas y vino) y después los productos denominados en Francia grandes cultures, entre los que destacaban los cereales, los lácteos y el sector cárnico. Esta estructura conlleva también una división geográfica motivada por las condiciones climáticas que necesita cada uno de los productos. Las grandes cultures se situaban en el centro y norte de Francia, mientras que las explotaciones de frutas, verduras y vino se localizaban en la parte meridional del país y sobre todo en la franja mediterránea. No obstante, pueden aparecer ciertas excepciones, como los cultivos de manzanas en el valle del Loire. Las diferencias entre los dos tipos de agricultura no se reducían a la zona geográfica y climática, sino que económicamente tenían un peso muy diferente en las estadísticas anuales. Las grandes cultures en 1980 aportaron 109,8 millardos de francos a la producción agraria total, mientas que las frutas, verduras y el vino, 52 millardos $^{12}$. Esa diferencia se reflejaba igualmente en la cantidad de dinero recibida por el FEOGA (Fondo Europeo de Orientación y Garantía Agrícola), y de ahí que los agricultores del sur de Francia reclamaran mayor protección de las instituciones comunitarias ${ }^{13}$.

12. AGF, 1982, 45.

13. En 1975, por ejemplo, los productos lácteos recibieron el $38,4 \%$ del presupuesto, los cereales el $15 \%$, mientras que las frutas y verduras únicamente el 2,1\%. Archivo National de France (ANF), AG/5(3)/1794. «Informe sobre la importancia del Mercado Común en la agricultura francesa», 1978. 


\subsection{Los productos mediterráneos: verduras, frutas y vino}

Las siguientes tablas recogen la comparación de la producción, así como los datos del comercio de una muestra significativa de los productos de los dos países ${ }^{14}$.

TABLA 3

Comparativa de las producciones, importaciones y exportaciones de frutas y verduras, promedio 1975-1980 (en toneladas)

\begin{tabular}{lrrrrrr}
\hline & \multicolumn{2}{c}{ Producción } & \multicolumn{2}{c}{ Importación } & \multicolumn{2}{c}{ Exportación } \\
\hline & \multicolumn{1}{c}{ Francia } & \multicolumn{1}{c}{ España } & Francia & España & Francia & España \\
\hline Tomate & 709.053 & 2.249 .849 & 183.005 & 276 & 9.886 & 252.381 \\
Zanahoria & 482.385 & 103.360 & 82.370 & 12,3 & 44.501 & 9.091 \\
Coliflor & 444.112 & 199.158 & 8285 & 7 & 138.221 & 1.560 \\
Lechuga & 428.000 & 486.650 & 59.691 & 85 & 20.478 & 33.671 \\
Alcachofa & 104.107 & 277.593 & 40.230 & 9 & 4.754 & 32.306 \\
Calabaza & 97.983 & 68.619 & 11.023 & 3 & 986 & 18.697 \\
Judía verde & 78.766 & 217.526 & 27.329 & 4 & 1.965 & 33.839 \\
Espárragos & 46.415 & 42.508 & 188 & 5 & 9.567 & 142 \\
Berenjena & 24.264 & 106.808 & 32.376 & 5 & 8.560 & 2161 \\
Naranja & 1.993 & 4.270 .967 & 658.066 & 281 & 14.679 & 926.647 \\
Manzana & 2.625 .667 & 996.800 & 99.592 & 3.320 & 623.618 & 11.979 \\
Melocotón & 396.948 & 363.400 & 61.829 & 0 & 23.678 & 15.424 \\
Pera & 406.666 & 421.783 & 56.412 & 11.039 & 53.203 & 18.277 \\
Fresa & 76.242 & 53.766 & 12.572 & 0 & 14.006 & 9.392 \\
Cereza & 105.636 & 72.217 & 2.724 & 0 & 23.031 & 525 \\
Albaricoque & 76.774 & 150.333 & 9.814 & 0 & 978 & 17.119 \\
\hline
\end{tabular}

Fuente: FAOSTAT.

$\mathrm{El}$ análisis de los datos muestra una diferencia importante entre ambos países. En el caso español destaca el autoabastecimiento en prácticamente todos los cultivos (no se ven obligados a importar) e incluso la generalización de excedentes dedicados a la exportación. De esta manera, España se consolidaba como un proveedor importante de productos primarios para Europa gracias a dos elementos: los acuerdos comerciales firmados con la CEE y el proteccionismo de Estado, que limitaba las importaciones de aquellos productos que se cultivaban en España. Como se verá más adelante, la diversificación de la dieta en España también fue un factor importante que condicionó las importaciones, las exportaciones y el consumo interno.

14. Por motivos de espacio no se han incluido todos los cultivos; solo se han seleccionados aquellos que eran relevantes en la producción o importación para Francia. 
TABLA 4

Relación de productos y países productores europeos, promedio 1975-1980

(en toneladas)

\begin{tabular}{lrrrrr}
\hline & Fresa & Manzana & Melocotón & Pera & Naranja \\
\hline España & 53.766 & 996.800 & 363.400 & 421.783 & 4.270 .967 \\
Francia & 76.242 & 2.625 .667 & 396.948 & 406.666 & 1.993 \\
Grecia & 10.701 & 255.568 & 357.544 & 116.106 & 548.456 \\
Italia & 177.298 & 1.972 .667 & 1.281 .033 & 1.288 .533 & 1.591 .400 \\
Alemania & 62.045 & 2.164 .484 & 23.886 & 419.571 & - \\
\hline
\end{tabular}

Fuente: FAOSTAT; ANF, 19850746/3.

En el lado opuesto se encontraba la agricultura mediterránea francesa. Pese a que era un productor relevante de ciertos cultivos, las cifras de importaciones demuestran que Francia no lograba ser autosuficiente y debía acudir al mercado internacional para cubrir toda su demanda. Esta disparidad se reflejaba en las balanzas comerciales de este tipo de cultivos. En 1981, por ejemplo, España logró un balance positivo de 1.844.823 toneladas, mientras que el resultado global de Francia resultó negativo en 1.103.000 toneladas ${ }^{15}$. Tanto Francia como el resto de los países comunitarios solventaban ese déficit de frutas y verduras acudiendo al mercado italiano, pero sobre todo a terceros países mediterráneos. Entre ellos destacó España gracias a su cercanía y a la competitividad de sus precios. En 1981, Francia absorbió el 30\% de las exportaciones de frutas y verduras que España destinaba a la $\mathrm{CEE}^{16}$.

La Tabla 3 muestra las verduras francesas en función con su producción en orden de importancia. Excepto el tomate, que tiene unas dinámicas muy específicas, el análisis de las tres siguientes muestra que la competencia no era tan importante en los productos más relevantes para Francia. De todas ellas, solo en la lechuga las producciones y las exportaciones españolas suponían un verdadero riesgo para el comercio internacional francés. En zanahorias, coliflores y espárragos, aunque España era un productor importante, el destino era el autoconsumo y no la exportación. En las frutas sucedía algo similar. La agricultura al norte de los Pirineos destacaba por la producción de manzanas, melocotones, peras y fresas, de modo que la situación de competencia se reducía al melocotón y a la fresa, pues en el resto las diferencias de exportación eran demasiado amplias. Tal y como muestra la Tabla 4, Francia no era, ni el único productor de estas frutas, ni tampoco el

15. AGF, 1982, 108.

16. AMAE, 1930INVA/5151. Ministère des Affaires Étrangères, «Espagne: commerce extérieur secteur agro-alimentaire», 14/06/1982. 
principal, por lo que la lucha comercial no era una rivalidad francoespañola; de hecho, Italia sería el más damnificado. Además, en el caso del melocotón, España no era el único tercer país que comerciaba con la CEE, pues Grecia también vendía una parte importante de sus producciones al Mercado Común ${ }^{17}$. Otra gran diferencia entre ambos países era la variedad de cultivos. Al norte de los Pirineos centraban sus producciones en manzanas, melocotones, peras, cerezas y, en menor medida, fresas, mientras que en España la diversidad de frutas y verduras era mucho mayor. De esta manera, el país ibérico se convertía en un gran exportador de naranjas, alcachofas o albaricoques, unos productos en los que, como muestran las tablas, no había ninguna posibilidad de competencia ${ }^{18}$. En el levante español destaca la producción de cítricos hasta el punto de que se convirtió en el mayor exportador europeo, incluso por encima de Italia (Piqueras, 1997). Estos frutos, junto con las producciones de tomate de Almería y Canarias, entre otras regiones, eran los más importantes para las exportaciones españolas. Ambos cultivos permitieron mejorar las balanzas comerciales de España, tanto con respecto a Francia como las referidas a todo el extranjero.

Los datos de las tablas se pueden completar con otras características sobre estos frutos. Los productos hortofrutícolas son muy dependientes del clima, y a eso se une que las zonas mediterráneas poseen años muy variables en cuanto a precipitaciones y temperaturas se refiere. Todo ello provocaba que la cantidad total producida cada año fuese diferente y, mientras que algunos años se generaban grandes excedentes, en otras ocasiones se tenía que recurrir al mercado internacional. El caso de la pera es muy representativo. En 1978 Francia tuvo que importar 50.000 toneladas de España, África y Australia; sin embargo, en 1981 y 1982 se produjeron grandes protestas en Francia por la importación de pera española, debido a que la cosecha había sido mucho más elevada y temprana que en años anteriores ${ }^{19}$. Similar situación ocurrió en 1979 con las alcachofas. Francia tuvo que duplicar sus importaciones procedentes de España ante las heladas invernales ${ }^{20}$. En la manzana, los continuos excedentes en Francia provocaban almacenamientos masivos y derivaciones obligatorias de una parte de las producciones a la

17. AMAE, Nantes, 396PO/F/1119. Ministère de l'Agriculture, "Les productions méditerranéennes de la Communauté et l'adhésion de l'Espagne», 13/10/1976.

18. En los nueve primeros meses de 1979 la naranja fue el producto que más compró Francia a España. AGA, leg. R. 16548. "Carta de Federico Garayalde al ministro del comercio y turismo", 26/11/1979. Sobre la importancia de la naranja en España, véase PIQUERAS (1997).

19. AMAE, Nantes, 25POI/1845. «Informe de las Communautés Européennes», 29/05/1979; ANF, 19910275/20. "Comunicado de prensa del Ministerio de Agricultura», 21/07/1982.

20. AGA, leg. R. 16548. "Carta de Federico Garayalde al ministro de comercio y turismo", 19/02/1979. 
destilación alcohólica ${ }^{21}$. De todo ello se encargaba la PAC. Cuando las cosechas comunitarias eran suficientes como para autoabastecer a la Comunidad, desde Bruselas prohibían la importación de terceros países.Y en las épocas en las que los cultivos no satisfacían la demanda, reducían los costes aduaneros para aumentar la compra a países extracomunitarios.

El clima marcaba otra diferencia fundamental. Aunque en ambos países la mayoría de las zonas dedicadas a estos cultivos se encontraban en la costa mediterránea, las temperaturas en España posibilitaban una maduración más temprana, e incluso permitían que los cultivos fuesen anuales y no estacionales, por lo que las producciones no siempre coincidían en el mercado. En el caso de la fresa, como afirma Cécile Bernard (1992), los frutos españoles y franceses solo concurrían durante tres semanas. En la producción de tomates todavía es más clarificador. España producía tomates todo el año, mientras que Francia concentraba toda su producción en los meses veraniegos. Así, la competencia solo se daba en la estación estival. Ante esta situación, Francia diseñó un calendario que establecía las fechas en las que la importación estaba prohibida en función del producto y de la época de producción francesa. En condiciones normales, el tomate o las judías verdes españolas no se podían comercializar en Francia durante los meses veraniegos ${ }^{22}$.

Todos los datos aportados permiten hablar de una competencia parcial, pero no total, por dos grandes motivos. Primero, porque no afectaba a todos los productos: naranjas, albaricoques, cerezas, alcachofas o calabazas no tenían problemas de competencia. $\mathrm{Y}$, segundo, porque en aquellos productos en los que sí existía riesgo de competencia no siempre era completa. A excepción del melocotón y de la lechuga, en el resto de los productos, como se ha comentado en el caso del tomate o la fresa, se trataba de momentos puntuales. Además, Francia había impuesto medidas para impedir que dentro de sus fronteras se pudieran comercializar dichos cultivos. Esas políticas, tras la adhesión, se transformaron en periodos de transición largos y en limitaciones de producción y comercialización. Por otra parte, Francia también estaba negociando en la CEE para forzar la preferencia comunitaria e impedir que el resto de los socios comunitarios optaran por productos de terceros países a un precio menor.

La competencia sustitutiva y no complementaria fue también el argumento de los sectores vinícolas para oponerse a la adhesión de España. Consideraban -como concluyó una

21. AMAE, Nantes, 25POI/1845. "Informe enviado desde Bruselas al Gobierno francés», 13/08/1979.

22. ANF, 19850746/1. Chambre Régional d'Agriculture d'Aquitaine, «Note sur la production fruitière et légumière Aquitaine-Espagne", abril de 1978. ANF, 19850746/1. 
comisión del diario regional Midi Libre tras examinar los viñedos murcianos- que le vin espagnol peut, dans l'avenir, être un concurrent très sérieux pour nos propres vins ${ }^{23}$. Ese discurso fue defendido por la prensa, por la Assamblée Permanente de Chambres d'Agriculture, por gran parte de los líderes sindicales, como François Guillaume (FNSEA), por representantes políticos del RPR, del PCF e incluso por ciertos miembros del Gobierno $^{24}$. Sin embargo, antes de la demanda de adhesión de España, el Mercado Común ya tenía serios problemas con este producto: el consumo del vino estaba disminuyendo a una media de 0,9\% anual, mientras que la producción aumentaba (Camilleri, 1984: 278). Tras las protestas de los agricultores en Francia por la importación de vinos argelinos a bajos costes, apareció en 1974 la guerra del vino con Italia. El motivo era similar: Francia recurría a la compra de grandes cantidades de vino a granel a unos precios inferiores a los de su mercado ${ }^{25}$. Al mismo tiempo, los excedentes de 1974, 1979 y 1980 obligaron a replantear la PAC en un contexto en el que, como se ha comentado, el consumo estaba disminuyendo ${ }^{26}$. También aparecieron controversias en el seno de la CEE acerca de la carga fiscal al vino. Francia poseía uno de los impuestos más bajos al vino y se enfrentó a Gran Bretaña por su alta tasa impositiva a dicho producto, pues el alto gravamen fiscal no incentivaba su consumo (Tió, 1986: 99). Por otro lado, los viticultores del Midi veían cómo la mecanización eliminaba a parte de la mano de obra, además de que los beneficios cada vez eran menores en unas explotaciones todavía organizadas de manera familiar.

En este contexto, España solicitó la demanda de adhesión y la respuesta de los viticultores no se hizo esperar (Molina, 2018a; Trouvé, 2005). A priori, todo parece indicar que la integración de un país vinícola en un contexto de crisis del vino provocaría un ahondamiento de los problemas. Sin embargo, un análisis exhaustivo de los datos junto con algunos trabajos ya publicados sobre estas temáticas demuestra que la competencia sustitutiva podía ser matizada.

En primer lugar, tal y como demuestra la siguiente tabla, España no superaba las exportaciones de Italia y de Francia y, además, su productividad era mucho menor que la de los grandes productores comunitarios. No obstante, la posibilidad de crecimiento,

23. Midi Libre, 20/09/1980.

24. Algunos ejemplos, en Midi Libre, 17/01/1980 y 04/02/1981. El caso de las Chambres d'Agriculture, en ANF, 19840214/16.

25. Algunas noticias sobre dichos enfrentamientos, en feunes Agriculteurs, abril de 1975; L'Actuagri, 16/10/1976; L'Agrimidi, 13/04/1977 y 18/04/1977; Le Monde, 27/05/1977.

26. Una de las noticias que habla del asunto como un problema europeo y no español, en Midi Libre, 14/02/1980. 
como se verá en el siguiente apartado, sería uno de los argumentos más defendidos por Francia ante las instituciones comunitarias.

TABLA 5

Comparativa producción, superficie y rendimiento de uva, 1975 y 1982

\begin{tabular}{|c|c|c|c|c|c|c|}
\hline & \multicolumn{3}{|c|}{1975} & \multicolumn{3}{|c|}{1982} \\
\hline & $\begin{array}{c}\text { Superficie } \\
\text { miles ha }\end{array}$ & $\begin{array}{c}\text { Producción } \\
\text { miles de t }\end{array}$ & $\begin{array}{c}\text { Rendimiento } \\
\text { en kg/ha }\end{array}$ & $\begin{array}{c}\text { Superficie } \\
\text { miles ha }\end{array}$ & $\begin{array}{c}\text { Producción } \\
\text { miles de } t\end{array}$ & $\begin{array}{c}\text { Rendimiento } \\
\text { en } \mathrm{kg} / \mathrm{ha}\end{array}$ \\
\hline España & 1.700 & 5.777 & 3.398 & 1.658 & 6.028 & 3.844 \\
\hline Francia & 1.365 & 10.239 & 7.501 & 1.173 & 11.230 & 9.574 \\
\hline Italia & 1.400 & 11.043 & 7.888 & 1.377 & 11.150 & 8.098 \\
\hline
\end{tabular}

Fuentes: AAE (1976: 351); AGF (1982: 355).

En segundo lugar, los enfoques de producción y comercialización eran muy diferentes. Tal y como han demostrado Eva Fernández (2012) y Francisco J. Medina y José M. Martínez Carrión (2012), en España se apostó por un vino de baja calidad, mientras que en Francia, desde mediados de la década de los setenta, se orientó la producción hacia vinos de calidad. Ante la crisis en el sector, el Elíseo definió esa nueva política con el objetivo de diferenciarse del resto de los vinos comunitarios ante un consumidor que, aunque demandaba cada vez menos cantidad de vino, optaba por caldos de mejor calidad. Francia apoyó las denominaciones de origen como elemento de distinción y eso le permitió mejorar las ventas de esos vinos a principios de los ochenta un 9,5\%, mientas que los vinos de mesa disminuyeron un $8 \%{ }^{27}$. De esta manera, la competencia que podía suponer España a los vinos franceses solo afectaba al Midi, sobre todo a la región del Languedoc. En esta región se producía el $85 \%$ de los vinos de mesa de Francia (baja calidad $)^{28}$. Sin embargo, las grandes denominaciones de origen, como los vinos de Burdeos, no estaban preocupadas por esa competencia.

En tercer lugar, la balanza comercial del vino de ambos países muestra unas diferencias similares a las comentadas en el caso de las frutas y verduras. España apenas importaba vino, debido al proteccionismo y a que la demanda social correspondía a vinos de baja y media calidad ${ }^{29}$. El nivel adquisitivo de las familias todavía no había mejorado

27. AGF, 1983, 117. "Carta de la Oficina Comercial española en París al Ministerio de Exteriores», 24/02/1979; AGA, leg. R. 16548; RIES (1982: 82-83); ANF 19790026/25. «Informe Conseil Economique et Social», 28/09/1977.

28. Sobre la importancia del vino en dicha región, véanse Juge (2002), MARTIN (1997), LE BRAS (2013). Sobre el mercado internacional del vino, véanse ANDERSON y NELGEN (2011).

29. A esto se unía su menor consumo: en Francia era de 86 litros por persona y año, mientras que en España, de 51. AGF1982, 115-6; Tió (1986: 97). 
lo suficiente como para demandar vino de renombre. Al contrario, en Francia, a pesar de ser el segundo exportador mundial de vino tras Italia, las importaciones y las exportaciones estaban mucho más igualadas. Las condiciones climáticas de Francia impedían que sus vinos tuviesen una alta graduación alcohólica y la única manera de hacerlo era a través del proceso químico de chaptalización en los casos más extremos y de la mezcla con vinos más fuertes en la mayoría de las ocasiones ${ }^{30}$. Hasta la configuración del Mercado Común, las cooperativas francesas compraban esos vinos en Argelia, después pasaron a hacerlo en Italia y en menor medida en España. Ese es el motivo por el que España aparecía entre los proveedores de vino a granel (no embotellado) de Francia (Fernández, 2012: 66). Es decir, la adhesión perjudicaría a Italia porque las autoridades francesas podrían comprar en España el vino necesario para equilibrar sus caldos y todo ello a un precio menor.

TABLA 6

Balanza comercial agraria en toneladas de vino, 1976 y 1982

\begin{tabular}{ccccccc}
\hline & \multicolumn{3}{c}{1976} & \multicolumn{3}{c}{1982} \\
\hline & Importación & Exportación & Balanza comercial & Importación & Exportación & Balanza comercial \\
\hline España & 990 & 570.036 & +569.046 & 1.490 & 454.631 & +453.141 \\
Francia & 698.131 & 671.883 & -26.248 & 752.694 & 889.856 & +137.162 \\
\hline
\end{tabular}

Fuente: FAOSTAT.

La cuarta y última característica que diferenciaba ambas producciones era la orientación del mercado. Francia se consolidó en mercados extracomunitarios, ya que la CEE presentaba pocas posibilidades de crecimiento. Al igual que Italia, consiguió controlar el comercio del vino en EE. UU. España, por su parte, dirigió sus producciones a Europa (Gran Bretaña y Países Bajos) y en menor medida logró establecer un flujo comercial con la URSS $^{31}$.

En definitiva, las producciones mediterráneas de ambos países presentarían puntos en los que la competencia sería evidente. Sin embargo, no se puede generalizar y hablar de cultivos sustitutivos por diferentes motivos: los calendarios de producción y las condiciones climáticas imponían factores de distinción; la competencia no afectaba a todos los productos, porque cada país estaba especializado en unos productos diferentes; Francia no

30. Se trata de un proceso químico de azucarado del vino y se utiliza en aquellos caldos que no logran una fermentación alcohólica natural, debido a que el contenido de azúcar del vino no es suficiente (Tió, 1986: 99).

31. Según el Ministerio de Economía de Francia, solo la unión de cooperativas de La Mancha exportó $160.000 \mathrm{hl}$ a la URSS en 1980. ANF, 19880334/14. "Informe del Ministerio de Economía», 02/01/1980. Sobre las diferencias del mercado, véase FERNÁNDEZ (2012). 
podía autoabastecerse y eso le obligaba a recurrir a la importación; y, además, las políticas de calidades y comercialización diferían de manera significativa.

\subsection{Las grandes cultures}

Las condiciones climáticas y geográficas de Francia le permitieron desarrollar una agricultura polivalente. En el sur predominaron las plantaciones mediterráneas y en el centro y norte se implantaron las grandes cultures, gracias al mayor índice de precipitaciones. Los resultados globales de estas dos agriculturas fueron muy diferentes. Mientras que en la trilogía mediterránea Francia se tuvo que conformar con posiciones secundarias, en las grandes cultures se consolidó como el mayor productor europeo. Tanto en los cereales como en la ganadería (lechera o cárnica), las altas producciones le permitieron generar excedentes que comercializaba en Europa. A principios de la década de los ochenta, la producción de cereales francesa suponía el 38,5\% de la comunitaria, la cantidad de leche superaba el $29 \%$ del total de la CEE y la aportación en el sector cárnico se situaba en el 30,5\% (Camilleri, 1984: 415, 512) ${ }^{32}$.

Las grandes cultures (cereales, lácteos y carne) eran las más importantes en los balances finales de la producción agraria francesa, tal y como se avanzó al inicio del apartado ${ }^{33}$. Esa mayor relevancia se podía constatar en el protagonismo que tenían en la PAC y en los presupuestos comunitarios, lo que motivó continuas quejas de los agricultores mediterráneos. Denunciaban que la agricultura comunitaria funcionaba a dos velocidades, siendo las frutas, las verduras y el vino los productos más perjudicados en la mayoría de los casos. Por otra parte, a pesar de esa mayor protección legislativa, también aparecieron tensiones entre estos productos. En el sector lácteo, la generalización de excedentes obligó a replantear la PAC, a imponer unas cuotas máximas de producción y a promover la reconversión del sector (Petit, 2016: 57; Vercherand et al., 2012: 7). En la ganadería, los conflictos no fueron provocados por la aparición de remanentes, sino por competencias bilaterales, como la guerre du mouton, que enfrentó en 1979 a Francia y Gran Bretaña por las importaciones de ovinos ${ }^{34}$.

Tras conocer la importancia de estos tres sectores para Francia, quedaría contrastar dichos valores con los españoles para valorar hasta qué punto la adhesión ibérica pondría en peligro la hegemonía francesa en la CEE. Las tablas mostradas a continuación refle-

32. AGF, 1982, 90. Algunos datos más en AAE, 1983, 454.

33. AGF, 1982,45; AAE, 1983, 616.

34. AGAR. 16.568. «Carta del embajador español en París al Ministerio de Exteriores», 26/06/1979. 
jan que España no presentaría un riesgo para las grandes cultures francesas por diferentes motivos. En primer lugar, la modernización que se había llevado a cabo desde la década de los sesenta en España no fue tan relevante como en el resto de Europa. Se lograron cambios muy importantes en la ganadería porcina y avícola, hasta el punto de que el crecimiento de la carne aviar pasó del 2\% al 33\% entre 1960 y 1975 (Domínguez Martín, 2001: 58). Ese auge vino motivado por el incremento en el consumo de carne y la mejora de la dieta (Cussó \& Garrabou, 2007: 69-100): mientras que en 1960 en España se consumían 18 kilos por persona y año, en 1980 aumentó hasta los 64. Aun así, el desarrollo no le permitió situarse en los niveles comunitarios. La crisis del petróleo, las políticas proteccionistas y unas condiciones climáticas desfavorables, entre otros motivos, impidieron una homologación con Francia, un país con una trayectoria histórica en estos sectores mucho más longeva, racional y eficaz que la española.

En segundo lugar, los cereales de la península, como se muestra en la Tabla 7, eran menos productivos que los franceses, por lo que con las mismas hectáreas la cantidad recolectada era inferior. Las condiciones climáticas y la mayor mecanización al norte de los Pirineos son algunos de los factores que propiciaron tales diferencias. Además, las políticas franquistas en este sector, sobre todo en el trigo, fueron un fracaso, pese a que se trató, junto a la viticultura, de una apuesta de la dictadura (Barciela, 1981, 2003; Christiansen, 2012; Simpson, 1996). Esa desigualdad era esencial y desencadenaba una serie de consecuencias negativas para España. Los cereales tenían un doble fin. Por una parte, el consumo humano. Desde este punto de vista, en sociedades como la española, con un nivel adquisitivo menor, los productos fabricados a partir de cereales, como el pan, tenían un mayor protagonismo debido a su menor precio, aunque dichas dinámicas fueron evolucionando (Cussó \& Garrabou, 2007: 69-100). Por otra parte, los cereales eran la base de los piensos para el sector ganadero. Mientras España tenía que importar gran parte de los cereales, Francia se había convertido en el principal exportador comunitario, consiguiendo de esa manera una balanza comercial muy positiva ${ }^{35}$ (los datos de la Tabla 8 reflejan las diferentes realidades). Estas cifras provocaban que los cereales fuesen para Francia el ingrediente que revertía positivamente su balanza comercial, mientras que para España la dependencia cerealista fue un factor que frenó el desarrollo de la ganadería.

En tercer lugar, la producción de leche también era muy inferior a la comunitaria. En este caso, el motivo no era solo el menor rendimiento, sino la diferencia en el número de $\operatorname{vacas}^{36}$. En España este sector se concentraba en Galicia y Asturias, mientras que en Fran-

35. En el caso del maíz, Francia podía generar hasta un 150\% de excedentes, mientras que España solo cubría el 36\% de su demanda (CAMILleRi, 1984: 335; Tió, 1986: 53).

36. Aun así, existían diferencias significativas: en una reunión de análisis sobre la agricultura espa- 
cia existía un desarrollo importante del sector en todo el norte (Domínguez Martín, 2001: 63; Sobrino, 1983).

En cuarto lugar, el desarrollo del sector ganadero no era suficiente como para alcanzar la demanda de una sociedad que estaba empezando a incluir el consumo de carne en su dieta. A pesar de que el sector aviar consiguió un desarrollo considerable hasta 1975, a partir de ahí se agotó su crecimiento. Al mismo tiempo, el vacuno y el porcino, aunque aumentaron, no cubrieron toda la demanda, por lo que España continuó sujeto a las importaciones (Domínguez Martín, 2001: 66-76). No hay que olvidar que el funcionamiento de este sector dependía de los piensos de importación. De esta manera, España se tuvo que conformar entre 1975 y 1980 con un grado de autoabastecimiento del $75 \%$, que se alejaba del 95,4\% francés (Camilleri, 1984: 473, 478). Además, tal y como representa la Tabla 10, España solo exportaba más que importaba en el sector ovino. En ese tipo de ganado, Francia presentaba un déficit importante, por lo que no existiría competencia.

TABLA 7

Comparativa de las superficies, el rendimiento y las producciones, 1974-1976

\begin{tabular}{lcccccc}
\hline & \multicolumn{3}{c}{ Francia } & \multicolumn{4}{c}{ España } \\
\hline & $\begin{array}{l}\text { Miles } \\
\text { de ha }\end{array}$ & $\begin{array}{c}\text { Rendimiento } \\
\text { kg/ha }\end{array}$ & $\begin{array}{c}\text { Producciones } \\
\text { miles de t }\end{array}$ & $\begin{array}{c}\text { Miles } \\
\text { de ha }\end{array}$ & $\begin{array}{c}\text { Rendimiento } \\
\text { kg/ha }\end{array}$ & $\begin{array}{c}\text { Producciones } \\
\text { miles de t }\end{array}$ \\
\hline Trigo & 4.099 & 4.078 & 16.715 & 2.865 & 1.544 & 4.424 \\
Cebada & 2.753 & 3.375 & 9.303 & 3.176 & 1.848 & 5.868 \\
Maíz & 1.755 & 4.279 & 7.511 & 472 & 3.765 & 1.777 \\
\hline
\end{tabular}

Fuente: AAE (1983: 54-56, 64, 77).

En definitiva, en los sectores más importantes para la PAC y para el comercio exterior mundial, Francia era la potencia más importante del contexto comunitario y esa situación privilegiada convertía a las grandes cultures en el pilar de su agricultura; de ahí que representantes de estos cultivos controlaran las organizaciones agrarias e incluso el Ministerio de Agricultura. En el polo opuesto se encontraba España, que no pudo desarrollar dichos sectores, y eso le provocó una dependencia exterior importante. Desde el Ministerio de Agricultura español, entre 1978-1981, Jaime Lamo de Espinosa intentó poner remedio al problema de esos sectores a través de medidas financiadoras y promoción de la ganadería intensiva, pero el aislamiento del mercado español provocaba que se mantuviese alejado de la realidad comunitaria (Sumpsi, 1983: 463-466).

ñola se mostró la ineficiencia de la agricultura del norte peninsular, caracterizada por pequeñas explotaciones familiares sin mecanización. Sobre los resultados de ese encuentro, véase AsociacióN EsPaÑola DE ECONOMÍA Y SOCIOLOGÍA AgRARIA (1977: 44). 
TABLA 8

Evolución de las balanzas comerciales en cereales, 1975-1980 (en toneladas)

\begin{tabular}{llrrrrrr}
\hline & & \multicolumn{1}{c}{$\mathbf{1 9 7 5}$} & \multicolumn{1}{c}{$\mathbf{1 9 7 6}$} & $\mathbf{1 9 7 7}$ & $\mathbf{1 9 7 8}$ & $\mathbf{1 9 7 9}$ & $\mathbf{1 9 8 0}$ \\
\hline Trigo & España & -22.707 & -66.935 & -198.440 & -217.686 & -223.450 & -259.722 \\
& Francia & 2.475 .792 & 2.892 .908 & 2.309 .004 & 3.224 .629 & 3.990 .006 & 3.949 .931 \\
\multirow{2}{*}{ Cebada } & España & 28.252 & 253.764 & 2.397 & 678 & -9.103 & -553.731 \\
& Francia & 2.475 .792 & 2.892 .908 & 2.309 .004 & 3.224 .629 & 3.990 .006 & 3.729 .931 \\
\multirow{4}{*}{ Maíz } & España & -4.179 .769 & -3.538 .717 & -4.119 .559 & -4.356 .831 & -4.368 .467 & -4.531 .740 \\
& Francia & 2.020 .449 & 1.117 .381 & 746.734 & 1.663 .435 & 2.377 .042 & 2.653 .285 \\
\hline
\end{tabular}

Fuente: FAOSTAT.

TABLA 9

Estadísticas de la leche fresca de vaca, promedio 1975-1980

\begin{tabular}{lccc}
\hline & Número de vacas (en miles) & Rendimiento $\mathbf{k g} / \mathbf{a n ̃ o}$ & Producción miles de t \\
\hline España & 1.933 & 2.631 & 5.028 \\
Francia & 10.142 & 3.010 & 30.504 \\
\hline
\end{tabular}

Fuente: AAE (1983: 454).

TABLA 10

Balanzas comerciales de carne, promedio 1975-1980 (en toneladas)

\begin{tabular}{lrrrr}
\hline & Vacuno & Ovino & Porcino & Avícola \\
\hline España & -47.807 & 1.150 & -32.673 & -7.619 \\
Francia & 15.469 & -44.059 & -184.653 & 122.382 \\
\hline
\end{tabular}

Fuentes: FAOSTAT; AAE (1983: 425-445).

TABLA 11

Evolución de la balanza comercial lácteos y huevos, 1975-1980 (valor en 1000 \$)

\begin{tabular}{lcccccr}
\hline & $\mathbf{1 9 7 5}$ & $\mathbf{1 9 7 6}$ & $\mathbf{1 9 7 7}$ & $\mathbf{1 9 7 8}$ & $\mathbf{1 9 7 9}$ & $\mathbf{1 9 8 0}$ \\
\hline España & -97.941 & -67.759 & -49.896 & -57.198 & -110.360 & -86.230 \\
Francia & 701.649 & 690.052 & 925.236 & 821.493 & 1.203 .524 & 1.510 .926 \\
\hline
\end{tabular}

Fuente: FAOSTAT.

\section{Y, ¿ENTONCES?}

Todo lo anterior muestra que la competencia no era total, sino que se reducía a una zona concreta de Francia conocida como el Midi (regiones del sureste en la costa mediterránea) y a unos productos determinados. Esas mismas visiones se encontraban en los informes que encargaba el propio Gobierno francés a especialistas en estos temas, tanto del Ministerio de Economía como del de Agricultura. Todos ellos coincidían en señalar que, 
si bien España presentaría ciertos problemas en el sector agrario, no se podía generalizar la problemática. En el sector de la carne, fue el propio embajador francés quien le reconoció a su ministro de Exteriores que los sectores ganaderos españoles no serían un problema para los productores franceses, pues, para empezar, debían realizar reformas para poder adaptarse (Roux, 1988: 370-371) ${ }^{37}$. El Ministerio de Industria iba más allá y consideraba que le marché espagnol pourrait absorber 70.000 à $80.000 t$ par an de viande bo$v_{i n}{ }^{38}$. Es decir, no solo no sería competencia, sino que la integración española permitiría aumentar las exportaciones al sur de los Pirineos. En el sector lechero y en el cerealista la situación era todavía más evidente, pues la diferencia con respecto a los españoles era todavía mayor. Eso permitió que desde Francia se iniciaran negociaciones para aumentar las exportaciones a España y que, incluso desde las regiones del sur, se reconociera que sería un beneficio para el maíz que producían ${ }^{39}$; es más, no solo se valoró positivamente la adhesión para las grandes cultures, sino también para ciertos productos mediterráneos. Los documentos internos de la Administración francesa certificaban que los vinos de calidad (con denominación de origen) no sufrirían la competencia española por su diferente enfoque productivo y que, por tanto, sería Italia el principal perjudicado. De hecho, dicha integración les permitiría realizar compras a granel a España para aumentar la graduación de sus vinos a un menor coste que en Italia. A todo ello se sumaron ciertas críticas a los viticultores del Midi, acostumbrados -según dichos documentos-a conformarse con las ayudas estatales y a protestar en lugar de dedicar sus esfuerzos a la mejora de la calidad y la comercialización de unos vinos inadaptados a las demandas sociales ${ }^{40}$. La región del Midi utilizó el tema de la adhesión de España para presionar al Gobierno. Su objetivo era que los representantes políticos defendiesen un cambio de la PAC en Bruselas, para igualar el reglamento de los productos mediterráneos al de las grandes cultures. Por tanto, este conflicto no debe entenderse como algo exclusivamente bilateral. Las declaraciones de los líderes sindicales contra sus propios gobernantes o los boicots con-

37. ANF, 19920406/5. «Carta del embajador Margerie al ministro de Exteriores», 22/10/1979. En una reunión bilateral se cuantificaron las cantidades que importaría España: leche francesa, maíz americano y argentino y vacuno argentino. Los resultados de ese encuentro los publicó la AsociACIÓN EsPaÑola DE ECONOMÍA y Sociología AgRARIA (1977: 35); AGA, leg. R.16.571. «Informe sobre el estado de las negociaciones", enero de 1979.

38. AMAE, 1929INVA/4382. "Informe del Ministerio de Industria sobre las consecuencias de la adhesión", 21/03/1977.

39. ANF, 19850746/3. «Informe del Institut d'Economie Régionale du Sud-Ouest», diciembre de 1980; Le Figaro, 09/02/1979.

40. ANF 19880334/14. "Informe del Ministerio de Economía sobre el impacto de los vinos españoles», 02/01/1980; AGAR. 16.570. "Consulado de Burdeos al Ministerio de Exteriores español», 21/10/1978; AGA, leg. R.16548. "Oficina Comercial española en Francia», 24/02/1979; ANF 19920406/3. «Informe del Ministerio de Exteriores para discutir en la Comisión mixta CEE-España», 21/09/1977. 
tra edificios institucionales, y no solo contra los cargamentos de frutas españolas, son algunos de los ejemplos que demuestran dicha hipótesis ${ }^{41}$. El Gobierno, por su parte, tuvo que tomar medidas, como el proyecto del Grand Sud-Ouest, para reforzar las economías regionales del sur del país antes de las integraciones mediterráneas.

Aun así, también es necesario aludir a algunas de las críticas realizadas desde Francia a la agricultura española al margen de los datos aportados anteriormente: En primer lugar, temían el incremento de la productividad española tras la adhesión gracias a la mecanización del agro español. La introducción del regadío en la viticultura era uno de sus mayores miedos, pues podría provocar que el rendimiento por hectárea aumentase. Este miedo obligó al Ministerio de Agricultura de España a cancelar su proyecto de ley de regadío para evitar dar argumentos a las instituciones galas ${ }^{42}$. En segundo lugar, criticaron el exceso de proteccionismo de la agricultura española como herencia de la dictadura. Esa situación permitía a España exportar a Europa con condiciones aduaneras favorables, mientras que las autoridades españolas mantuvieron limitadas las importaciones gracias al acuerdo preferencial de 1970; de ahí los continuos intentos de Francia en Bruselas de presionar para acabar con dicho acuerdo. Estudios más recientes han demostrado que ese proteccionismo también acabó siendo una lacra para la agricultura española, porque aisló a ciertos productos de la realidad productiva y comercial internacional. Como analiza Rafael Domínguez, el aislamiento del sector lechero benefició la incompetencia del sector (Domínguez Martín, 2001: 62). En tercer lugar, desde Francia se criticó la política de precios y salarios de España, porque se encontraban por debajo de los comunitarios, lo que impedía una competencia leal entre los productos españoles y franceses. Se denunciaba, por ejemplo, que la producción de vino en España era un $43 \%$ más barata ${ }^{43}$. No obstante, para esta problemática la CEE tenía mecanismos para impedir que los productos españoles entrasen en el mercado comunitario a precios de dicho país: las aduanas, los precios referencia o los calendarios de protección comentados en el primer apartado impedían en la mayoría de los casos el dumping comercial. Por último, la cuarta condición que ponía a España era la preferencia comunitaria. Hasta ese momento, como se ha visto en el apartado anterior, en cereales (sobre todo piensos) y en carne (mayormente bovina) el país ibérico tenía que recurrir a mercados internacionales para cubrir con su demanda: compraba en América (los cereales a EE. UU. y las carnes a Argentina), debido a que los

41. En Perpignan los agricultores tiraron 10 toneladas de lechuga francesa en la puerta de la prefectura (Midi Libre, 21/01/1982). Otro ejemplo en Midi Libre, 08/02/1982. Todo ello se puede reforzar conociendo la actividad del Comité d'action viticole (SMITH, 2013).

42. Entrevista a Jaime Lamo de Espinosa realizada por miembros del SEFT (Seminario de Estudios del Franquismo y Transición) el 22 de junio de 2018.

43. ANF, 19880334/10. «Informe del Ministerio de Agricultura para el grupo de trabajo de Problemas Mediterráneos», 05/05/1977. 
precios eran inferiores a los comunitarios. Dada esta situación, Francia puso como condición a una futura adhesión que dichas importaciones las enfocara al mercado francés y no al internacional ${ }^{44}$. Fue el propio Valery Giscard d'Estaing quien le recomendó a Juan Carlos I que reorientara el comercio español hacia productos europeos ${ }^{45}$. No obstante, en este apartado hubo conflictos, ya que Francia optó por defender su comercio de berenjenas y plátanos con las Antillas a pesar de que España producía ambos productos ${ }^{46}$.

Se han mostrado argumentos suficientes como para poder afirmar que la competencia no era común a todos los productos agrícolas y que, además, el propio Gobierno conocía la verdadera situación de ambos sectores primarios. De esta manera se puede certificar que el orden económico no es suficiente para justificar el bloqueo de la adhesión. Los beneficios de los sectores de las grandes cultures, de los vinos o incluso de los cítricos, en una valoración global, podrían ser mayores que las pérdidas en ciertas frutas y hortalizas. Por tanto, llegado este punto, consideramos que el orden político jugó un papel esencial en las negociaciones. Aunque no es objeto de análisis en este artículo, se mostrarán algunas de las pautas que es necesario trabajar sobre la importancia del debate político en las cuestiones agrarias. En primer lugar, se deben diferenciar los múltiples niveles de la política: nivel social (movimientos sociales), nivel nacional y política diplomática. En el primero de ellos, las asociaciones y la prensa regional del Midi mantuvieron unos discursos muy belicosos, que se tradujeron en acciones violentas en la frontera pirenaica (Molina, 2018a). El diario L'Indépendant llegó a afirmar: ils assassinent notre région ${ }^{47}$. Las regiones del sur estaban sufriendo una crisis agrícola importante desde principios de la década que desembocó en conflictos con su propio Gobierno (Touraine \& Dubet, 1983). En las políticas nacionales se utilizó el tema de la adhesión con objetivos electorales. En Francia, sobre todo el PCF (Parti comunniste français) y el RPR construyeron discursos con el propósito de desgastar al Gobierno, hasta que, tras las elecciones de 1981, se dieron cuenta de que dichos discursos no habían funcionado ${ }^{48}$. Por otra parte, en España también se sirvieron de las objeciones francesas para justificar el retardo de la adhesión.

44. ANF, 19920406/5. "Carta de la Dirección de ganaderías y productos lácteos a Lachaux", 23/02/1980; ANF, 19920406/5. "Resumen francés de la reunión sobre la negociación de la adhesión», 13/11/1979; $\operatorname{AAE}(1983: 423)$.

45. ANF, AG/5(3)/1803. «Nota de Polge de Combret para el presidente francés sobre la entrevista con el rey de España», 28/10/1976.

46. Informe de la Comisión de la CEE. AMAE, Nantes, 25POI/1/1845. «Proposición de ayuda a la comercialización de berenjenas y productos de las Antillas francesas», 02/07/1979.

47. L'Indépendant, 24/09/1978.

48. AGA, 23 top 31/12. "Informe realizado por Daniel Busturia tras reunirse en París con RPR», 05/09/1979; Ya, 24/09/1977; fax del Ministerio de Asuntos Exteriores de Francia. AMAE, 1929INVA/4383. «PCF y la entrada de España en la CEE», 05/12/1978. 
Tal y como demuestra el transcurso de las negociaciones, hubo más motivos de retraso: el conflicto de la pesca o la necesidad de adaptarse al reglamento fiscal comunitario son algunos de los ejemplos más importantes. De hecho, Jaime Lamo de Espinosa y Eduardo Punset reconocieron que habían alimentado el discurso de la responsabilidad francesa ${ }^{49}$, lo que permitió al Gobierno eludir ciertas responsabilidades. El último nivel es el diplomático. En este caso es fácilmente comprobable la tensión en las negociaciones, pero también los momentos de entendimiento. Ambos países eran conscientes de que la integración era cuestión de tiempo, de ahí que firmaran numerosos acuerdos comerciales, como el intercambio de productos agrarios o la compra española de Airbus y de aviones militares. Dentro de esos encuentros, ambos países se confesaban sus intereses particulares. Francia pedía la reforma de la PAC y esperar el paso de las elecciones presidenciales de 1981 para la adhesión, mientras que España intentaba adelantar las negociaciones antes de los comicios de 1982, para que el Gobierno de la UCD pudiera utilizar estos argumentos en la campaña electoral.

Por cuestiones de espacio, el análisis se ha centrado en los productos frescos, pero la industria agroalimentaria también formó parte de las negociaciones. La tecnificación estaba provocando cambios a la hora de entender el sector (Malassis, 1997). Si en 1962 solo el $56,2 \%$ de los productos frescos pasaban por la industria alimentaria, en 1980 dicho porcentaje aumentó hasta el 74,2\% (Abad \& Naredo, 2002: 88). Los bajos costes de los productos agrarios en España, junto con los excedentes acumulados, permitieron que dicho sector se desarrollara de manera muy importante en los setenta gracias al capital extranjero. Concretamente, España se especializó en las conservas de tomate y en menor medida de melocotón ${ }^{50}$. En relación con esta tipología industrial existen informes contradictorios. Mientras que unos afirmaban que España no sería competencia, otros concluían que perjudicaría a las empresas francesas dedicadas a estos productos ${ }^{51}$. Lo que sí se puede afirmar es que, de nuevo, el país más damnificado no sería Francia, sino Italia, pues producía cantidades mucho mayores ${ }^{52}$.

49. AMAE, 1929INVA/4382. «Entrevista a Jaime Lamo de Espinosa realizada por miembros del SEFT», 22/06/2018; «Visita de Punset a París», octubre de 1980.

50. Con respecto al melocotón, Grecia era el principal competidor para Francia. Fax de Nanteuil, embajador francés en Bruselas, "Memorándum sobre la importación de melocotón en almíbar de Grecia», 04/07/1979. AMAE Nantes, CAJA 25POI/1/1845.

51. AMAE, 1929INVA/4392. Carta de la Embajada en Madrid, «Eficacia de las industrias agroalimentarias en España», 11/12/1979; AMAE, 1929INVA/4392. "Resumen de la visita de la Comission de la Production et des Échanges de l'Assamblée National a España», 23/09/1977.

52. AMAE, Nantes, 25POI/1/1845. Comisión de la CEE, «Problemas relativos a la ayuda de ciertos productos elaborados", 25/05/1979. 


\section{CONCLUSIONES}

El análisis realizado a través de las estadísticas agrarias y completado con documentación primaria ha permitido responder a la pregunta inicial. No se puede hablar de una competencia total entre las agriculturas española y francesa, sino que más bien se trataba de una competencia parcial por dos motivos: primero, porque no afectaba a todos los productos; y segundo, porque en algunas ocasiones dicha competitividad se reducía a un periodo de tiempo muy concreto. Las lechugas eran uno de los cultivos más afectados, el comercio del tomate solo coincidía en la época estival y, en el caso de las naranjas o la leche, no existía ningún tipo de problemas. A estas conclusiones ha sido posible llegar gracias a los datos cuantitativos, pero también a los propios informes que elaboraron los diferentes ministerios franceses. Desde sus propias instituciones conocían la situación real de ambos sectores primarios. Esto último es esencial para comprender que dicha problemática no puede ser abordada únicamente desde un punto de vista económico.Y esa ha sido la segunda aportación del artículo. Las estadísticas de producciones y balanzas comerciales no han mostrado argumentos suficientes como para poder explicar que ese debate se alargara hasta 1985 . Una vez conocida la complejidad de la cuestión, todo apunta a que los factores políticos fueron esenciales, es decir, se produjo una politización de la cuestión. Para ello, no hay que olvidar ninguno de los dos contextos nacionales. En Francia, la agricultura del Midi se encontraba en crisis, descontenta con su propio Gobierno por su poco protagonismo frente a las grandes cultures y, además, en contra de una PAC claramente desfavorable para sus intereses. Por otro lado, en España la adhesión a Europa serviría para legitimar la democracia y también para reforzar al gobierno de la UCD, cada vez más deteriorado por el desencanto social, las pugnas internas y las presiones del sindicalismo agrario. Ante esta situación, Giscard d'Estaing, tras comprender la verdadera situación agrícola, tuvo que enfrentarse al uso que hizo la oposición de esta cuestión para desgastarle, a las presiones agrarias e industriales -estos últimos para que favoreciera la adhesión-y también a las autoridades comunitarias. Todo apunta a que el Gobierno francés tuvo que nadar y guardar la ropa, pues tampoco se debe olvidar que la apertura internacional de España supuso una carrera entre Francia, Alemania y EE. UU. por conquistar ese nuevo mercado. Al sur de los Pirineos, Adolfo Suárez también tenía motivos suficientes para mantener un discurso que justificara el retraso de la adhesión como un problema francés. De esa manera evitaba hablar de las modificaciones que debía hacer en clave interna antes de la adhesión, pues muchas de ellas provocarían efectos negativos. Esta situación comenzó a cambiar a partir de 1983 y 1984 gracias a cambios políticos y acuerdos europeos. Las elecciones nacionales en España de 1982 dieron paso a un gobierno socialista que cambió la dinámica de las negociaciones, en parte -aunque no fue el único motivo- por la cercanía ideológica entre Mitterrand y González; pero, sobre todo, el acuerdo de Fontainebleau 
de 1984 fue el que habilitó una nueva etapa en la relación con Francia y en las negociaciones para la adhesión.

En definitiva, el análisis cuantitativo de las agriculturas ha permitido comprobar que no se trató básicamente de una cuestión económica y que ambos gobiernos eran conscientes de ello. Una vez realizada esta comprobación, en sucesivas investigaciones se ahondará en la incidencia de los factores políticos en clave regional, nacional y europea. Todo apunta a que serán dichos elementos los que ayuden a comprender por qué se alargó el debate agrario francoespañol.

\section{AGRADECIMIENTOS}

Me gustaría agradecer los comentarios aportados por los miembros del Seminario de Estudios del Franquismo y Transición (SEFT), así como las valoraciones de los revisores de Historia Agraria. Todas las apreciaciones han servido para mejorar considerablemente el artículo.

\section{REFERENCIAS}

ABAD, C. \& NAREDO, J. M. (2002). Sobre la «modernización» de la agricultura española: De la agricultura tradicional hacia la capitalización agraria y la dependencia asistencial. En C. Gómez Benito \& J. J GonzÁlez (Coords.), Agricultura y sociedad en el cambio de siglo (pp. 81-142). Madrid: McGraw Hill.

ANDERson, K. \& Nelgen, S. (2011). Global Wine Markets, 1961 to 2009: A Statistical Compendium. Adelaide: University of Adelaide Press.

Asociación EsPaÑola de ECONOMía y SOCIOLOGÍa AgraRias (1977). La incorporación de la agricultura española al Mercado Común Europeo. Madrid: Instituto de Relaciones Agrarias.

BARCIELA, C. (1981). La agricultura cerealista en la España contemporánea, el mercado triguero y el servicio nacional del trigo. Tesis doctoral. Madrid: Universidad Complutense de Madrid.

BARCIELA, C. (2003). El fracaso de la política agraria del primer franquismo, 1939-1959: Veinte años perdidos para la agricultura española. En C. BARCIELA (Coord.), Autarquía y mercado negro: El fracaso económico del primer franquismo, 1939-1959 (pp. 5594). Barcelona: Crítica.

BERNARD, C. (1992). Les productions de fraise à Huelva: Les avantages de la filière espagnole sur le marché européen. Économie rurale, (212), 12-18. 
BERTRAND, H. (2010). Les agriculteurs dans la vie politique française: Cinquante ans d'évolution, quatre regards. En H. BERTRAND et al., Les mondes agricoles en politique (pp. 19-38). Paris: Presses de Sciences Po.

BessiÈre, C. (2014). Introduction: Les agriculteurs dans la France contemporaine, Sociétés contemporaines, (96), 5-26.

Blumann, C. (Dir.) (2009). Politique agricole commune et politique commune de la pêche. Bruxelles: Université de Bruxelles.

BRUNETEAU, B. (1993). De la violence paysanne à l'organisation agricole: Les manifestations de juin 1961 en pays bigouden. Annales de Bretagne et des pays de l'Ouest, 100 (2), 217-232.

Bucarut, J. M., Moyne, V. \& Pollina, L. (1996). L'agriculture depuis 1949: Croissance des volumes, chute des prix. INSEE, (430), 1-4.

Bureau, J. C. \& Thoyer, S. (2014). La politique agricole commune. Paris: La Découverte. Busturia, D. DE \& CANTERA, G. (Coords.) (1994). Del reencuentro a la convergencia: Historia de las relaciones bilaterales hispano-francesas. Madrid: Ciencias de la Dirección.

CAMILleRI, A. (Coord.) (1984). La agricultura española ante la CEE. Madrid: Instituto de Estudios Económicos.

CASTRO, R. (2010). Génesis y transformación de un modelo de inversión internacional: El capital francés en la España del siglo XX. Tesis doctoral. Madrid: Universidad Complutense de Madrid.

Cavallaro, M. E. (2013). La Francia di Giscard d'Estaing da madrina ad ostacolo dell'integrazione della Spagna in Europa. En M. J. Cavallaro \& G. Levi (Eds.), Italia e Spagna nel processo di integrazione europea (1950-1992) (pp. 99-121). Soveria Mannelli: Rubbettino.

Centre NATIONAL DES JeUnes AgRiculteurs (CNJA) (1976). Espagne: Un choc pour l'Europe. Paris: CNJA.

Christiansen, T. (2012). The Reason Why: The Post Civil-War Agrarian Crisis in Spain. Zaragoza: Prensas Universitarias de Zaragoza.

Chupin, I. \& MAYANCE, P. (2016). L'agriculture en représentation(s): Luttes médiatiques, luttes syndicales. Études rurales, (198), 9-24.

Clar, E. (2005). Del cereal alimento al cereal pienso: Historia y balance de un intento de la autosuficiencia ganadera: 1967-1972. Historia Agraria, (37), 513-544.

Clar, E., Martín Retortillo, M. \& Pinilla, V. (2015). Agricultura y desarrollo económico en Espana, 1870-2000. Sociedad Española de Historia Agraria-Documentos de Trabajo, (1503), 1-44.

Clar, E., Serrano, R. \& Pinilla, V. (2015). El comercio agroalimentario español en la segunda globalización, 1951-2011. Historia Agraria, (65), 149-186. 
Cussó, X. \& GarRabou, R. (2007). La transición nutricional en la España contemporánea: Las variaciones en el consumo de pan, patatas y legumbres (1850-2000). Investigaciones de historia económica, (7), 69-100.

DomínGUEZ MARTín, R. (2001), Las transformaciones del sector ganadero en España (1940-1985). Ager: Revista de estudios sobre despoblación y desarrollo rural, (1), 4783.

FERNÁNDEZ, E. (2012). Especialización en baja calidad: España y el mercado internacional del vino, 1950-1990. Historia Agraria, (56), 41-76.

Hervieu, B. \& Purseigle, F. (2013). Sociologie des mondes agricoles. Paris: Armand Colin.

Juge, J. P. (2002). Le Midi du vin: De la crise à l'ambition. Portet-sur-Garonne: Loubatières.

LE BRAS, S. (2013). Les viticulteurs languedociens face à la politique communautaire. L'impossible pas de deux (1957-années 2000). En L. JalaberT \& C. Patillon (Dirs.), Mouvement paysans face à la politique agricole commune et à la mondialisation (1957-2011) (pp. 211-230). Rennes: Université de Rennes.

LEMUS, E. (2005). Las posiciones francesas ante la desaparición de Franco y el establecimiento de la monarquía. Historia del presente, (6), 61-84.

MALAssis, L. (1997). Les trois âges de l'alimentaire: Essai sur une histoire sociale de l'alimentation et de l'agriculture. Vol. 3. Paris: Cujas.

MARTin, J. P. (1997). Le syndicalisme viticole en Languedoc sous la Ve République. Économie rurale, (237), 44-48.

MARTin-PAÑEDA, P. (2015). Que dire à l'Espagne?: De l'isolement franquiste à la démocratie européiste, la France au défi, 1957-1979. Bruxelles: Peter Lang.

Medina, F. \& Martínez Carrión, J. M. (2012). La competitividad de las exportaciones de vino español y el mercado mundial, 1960-2011. Working Papers (Universitat Autònoma de Barcelona. Unitat d'Història Econòmica), (3), 1-23.

MEDINA, F. (2016). Intervención estatal del sector vitivinícola español durante el franquismo: Las bodegas cooperativas. International Conference "Old and New Worlds: The Global Challenge of Rural History". Lisboa, 27-30 de enero.

Molina, S. (2018a). La construcción del enemigo: Francia, España y el problema agrario, 1968-1977. Pasado y Memoria, (18), 453-477.

Molina, S. (2018b). La guerra de los camiones de 1980: Conflictos franco-españoles durante las negociaciones de adhesión a la CEE. XIV Congreso de la Asociación de Historia Contemporánea «Del siglo XIX al XxI:Tendencias y debates». Alicante, 20-22 de septiembre.

MORÁN, S. (1996). La cooperación hispano-francesa en la lucha contra ETA. Madrid: Universidad Complutense de Madrid. 
NúÑEZ PeÑAs,V. (2013). Entre la reforma y la ampliación (1976-1986): Las negociaciones hispano-comunitarias en tiempos de transición y «approfondissement». Tesis doctoral. Madrid: Universidad Complutense de Madrid.

Patel, K. K. (Ed.) (2009). Fertile Ground for Europe?: The History of European Integration and the Common Agricultural Policy since 1945. Baden-Baden: Nomos.

Petit,Y. (2016). La politique agricole commune PAC: Au coeur de la construction européene. Paris: La documentation française.

PIQUERAS, J. (1997). La naranja en España: 1850-1996: Exportación y especialización regional. Actas delVI Congreso de la Asociación Española de Historia Económica (pp. 160174). Girona, 15-17 de septiembre.

RIEs, A. (1982). El ABC del Mercado Común Agrícola. Madrid: Mundi-Prensa.

RoGER, A. (2011). Syndicalistes et poseurs de bombes: Modalités du recours à la violence dans la construction des «intérêts vitivinicoles» languedociens. Cultures $\mathcal{E}$ Conflits, (8182), 49-80.

Roux, B. (1988). L'adhésion de l'Espagne à la communauté économique européenne: La question agricole. Revue géographique des Pyrénées et du Sud-Ouest, (59-4), 353389.

SÁNCHEZ SÁNCHez, E. (2006). Rumbo al sur: Francia y la España del desarrollo, 19581969. Madrid: Consejo Superior de Investigaciones Científicas.

SARTorius, N. \& SABio, A. (2007). El final de la dictadura: La conquista de la democracia en España. Madrid: Temas de Hoy.

Simpson, J. P. (1996). Cultivo de trigo y cambio técnico en España, 1900-1936. Noticiario de historia agraria, 6 (11), 39-56.

SMITH, A.W. M. (2013). The Comité Régional d'Action Viticole (CRAV): Regional Identity, Violence and the Challenges of Modernisation in the Languedoc (1944-1992). Tesis doctoral. London: Queen Mary University of London.

SoBRINo, J. M. (1983). La situación regional en las comunidades europeas respectivas para Galicia. Santiago de Compostela: Universidad de Santiago de Compostela.

SolBes, P. (1979). La adhesión de España a la CEE: Los efectos sobre la protección exterior a la agricultura. Madrid: Moneda y Crédito. (Monografías de Moneda y Crédito, 2).

Sumpsi, J. M. (1982). La crisis de la agricultura moderna. Agricultura y Sociedad, (25), 185-193.

SuMPSI, J. M. (1983). La política agraria, 1968-1982. Papeles de Economía Española, (16), 322-334.

Tió, C. (1986). La integración de la agricultura española en la Comunidad Europea. Madrid: Mundi-Prensa.

Touraine, A. \& Dubet, F. (1983). El país contra el Estado: Luchas occitanas. Valencia: Institució Alfons el Magnànim. 
TrouvÉ, M. (2005). Une querelle agricole: Le Midi de la France et l'adhésion de l'Espagne à la CEE (1975-1986). Annales du Midi: Revue archéologique, historique et philologique de la France méridionale, (250), 203-227.

Trouvé, M. (2008). L'Espagne et l'Europe: De la dictature à l'Union européenne. Bruxelles: Peter Lang.

Vercherand, J., Lemery, B., Compagnone, C. \& Doidy, E. (2012). Le syndicalisme agricole face à la réforme de la PAC. Économie rurale, (330-331), 5-26. 